\title{
A Case of Long Partial Response to Combination Therapy of Bevacizumab and Capecitabine for Liver Metastases of Rectal Cancer
}

\author{
Atsushi Kawasaki ${ }^{a}$ Kenji Mimatsu ${ }^{a}$ Takatsugu Oida ${ }^{a}$ \\ Hisao Kanou ${ }^{\mathrm{a}}$ Youichi Kuboi $^{\mathrm{a}}$ Nobutada Fukino $^{\mathrm{a}}$ \\ Kazutoshi Kida ${ }^{a}$ Sadao Amano ${ }^{b}$

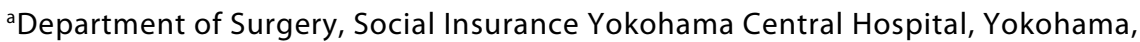 \\ and ${ }^{\text {bDepartment }}$ of Surgery, Nihon University School of Medicine, Tokyo, Japan
}

\section{Key Words}

Oxaliplatin · Neuropathy $\cdot$ Capecitabine $\cdot$ Bevacizumab $\cdot$ Colorectal cancer

\begin{abstract}
A 69-year-old female visited our department with a diagnosis of rectosigmoid cancer and multiple hepatic metastases (stage IV). Abdominal CT revealed multiple metastatic lesions in the bilateral lobes of the liver. The primary lesion was considered to be resectable, and high anterior resection of the rectum was performed. After the operation, 6 courses of therapy with bevacizumab (BV) and modified FOLFOX6 were performed. CT showed a partial response, and tumor marker levels became normal. After a total of 11 courses of this therapy, grade 3 peripheral neuropathy developed, and the therapy was changed to BV and capecitabine (Cape). After 6 courses of this therapy, CT showed the maintenance of partial response, and tumor marker levels were also within the normal range. BV and Cape therapy may be useful not only for reducing peripheral neuropathy, but also as a maintenance therapy in patients requiring the suspension of oxaliplatin administration due to peripheral neuropathy.
\end{abstract}

\section{Introduction}

After the introduction of FOLFOX therapy, the prognosis of advanced/recurrent colorectal cancer markedly improved [1]. However, in some patients, even though the antitumor effects of this therapy are observed, its continuation is difficult due to peripheral neuropathy caused by oxaliplatin. We report a patient in whom bevacizumab 


\begin{tabular}{r|l|l|l}
$\begin{array}{r}\text { Case Reports in } \\
\text { Gastruanteriology }\end{array}$ & $\begin{array}{l}\text { Case Rep Gastroenterol 2011;5:28-32 } \\
\text { DOI: 10.1159/000323138 }\end{array}$ & $\begin{array}{l}\text { Published online: } \\
\text { January 14, 2011 }\end{array}$ & $\begin{array}{l}\text { O 2011 S. Karger AG, Basel } \\
\text { ISSN 1662-0631 } \\
\text { www.karger.com/crg }\end{array}$ \\
\hline
\end{tabular}

(BV) + modified FOLFOX6 (mFOLFOX6) therapy was changed to BV + Cape therapy due to peripheral neuropathy, and the peripheral neuropathy decreased with partial response being maintained.

\section{Case Report}

A 69-year-old female with a past history of surgery for choledocholithiasis (details unknown) visited a local hospital due to melena. She was referred to our hospital under a diagnosis of rectosigmoid cancer with multiple hepatic metastases made by colonoscopy and abdominal ultrasonography. At the time of the first consultation at our department, the levels of CEA $(224.3 \mathrm{ng} / \mathrm{ml}$, normal range $<5 \mathrm{ng} / \mathrm{ml})$ and CA19-9 (444 U/ml, normal range $<37 \mathrm{U} / \mathrm{ml})$ as tumor markers were high. Colonoscopy revealed a type 2 lesion (2/3 of the circumference) in the rectosigmoid area (fig. 1). Abdominal CT showed multiple metastatic lesions in the liver (ig. 2a). The primary lesion was considered to be resectable, and high anterior resection of the rectum with D2 lymph node dissection was performed in December 2008. The histopathological diagnosis was moderately differentiated tubular adenocarcinoma, stage IV. Postoperative chemotherapy for the metastatic lesions of the liver, therapy with BV and mFOLFOX6 was initiated in January 2009 (chemotherapy consisted of an intravenous injection of oxaliplatin $85 \mathrm{mg} / \mathrm{m}^{2}$ with isovorin $200 \mathrm{mg} / \mathrm{m}^{2}$ over $2 \mathrm{~h}$ followed by 5 -fluorouracil (5-FU) $400 \mathrm{mg} / \mathrm{m}^{2}$ bolus and $2,400 \mathrm{mg} / \mathrm{m}^{2}$ continuous infusion over $48 \mathrm{~h}$ with BV $5 \mathrm{mg} / \mathrm{m}^{2}$, which was repeated every 2 weeks) (fig. 3). After 6 courses of this therapy (April 2009), the levels of CEA and CA19-9 as tumor markers decreased to $12.3 \mathrm{ng} / \mathrm{ml}$ and $48 \mathrm{U} / \mathrm{ml}$, respectively. The results of abdominal CT showed partial response (fig. 2b). A total of 11 courses were performed until July 2009, and both tumor markers improved to a normal level. However, since grade 3 peripheral neuropathy according to the Common Terminology Criteria for Adverse Events v. 3.0 (CTCAE v. 3.0) developed, the BV + mFOLFOX6 therapy was discontinued. Regimens involving oxaliplatin were considered difficult, and BV + capecitabine (Cape) therapy was initiated (BV $7.5 \mathrm{mg} / \mathrm{kg}$ on day 1 plus Cape $1,500 \mathrm{mg} / \mathrm{m}^{2}$ twice daily on days 1-14, every 3 weeks.). In January 2010, after 6 courses of BV + Cape therapy, the peripheral neuropathy disappeared, and the tumor marker levels (CEA $3.5 \mathrm{ng} / \mathrm{ml}$, CA19-9 9 U/ml) were within the normal range. Abdominal CT also showed the continuation of partial response (fig. 2c).

\section{Discussion}

FOLFOX therapy, first reported by de Gramont et al. in 2000, is a globally established standard therapy effective against advanced/recurrent colorectal cancer [1]. In addition, its combination with $\mathrm{BV}$ as a molecular targeted drug has markedly prolonged the survival period in patients with colorectal cancer [2]. However, drug accumulationassociated peripheral neuropathy as an adverse event specific to oxaliplatin used in this therapy is a major problem. As its cause, abnormality of the Na channel of neurons has attracted attention, but its detailed mechanism has not been clarified. The peripheral nerve symptoms induced by oxaliplatin are classified as acute or persistent. Persistent symptoms are defined in the oxaliplatin interview form as symptoms persisting for $\geq 14$ days that are accompanied by progressive sensory disturbance, hypesthesia, or the disappearance of somatic sensation, disturbing daily life. In general, when the aggravation of peripheral neuropathy, the delay in recovery, or sensory dysfunction develops, a reduction in the dose of oxaliplatin or suspension/discontinuation of its administration is necessary. Persistent peripheral neuropathy accounts for more than $30 \%$ of the causes of therapy discontinuation [3].

In our patient, after 11 courses of BV + mFOLFOX6 therapy, persistent grade 3 peripheral neuropathy developed, and discontinuation of this therapy was decided upon. About $90 \%$ of patients with severe peripheral neuropathy have been reported to show improvement 20 weeks after discontinuation of this drug [1]. Based on the results of our 


\begin{tabular}{r|l|l|l}
$\begin{array}{r}\text { Case Reports in } \\
\text { Gastruanterology }\end{array}$ & $\begin{array}{l}\text { Case Rep Gastroenterol 2011;5:28-32 } \\
\text { DOl: 10.1159/000323138 }\end{array}$ & $\begin{array}{l}\text { Published online: } \\
\text { January 14, 2011 }\end{array}$ & $\begin{array}{l}\text { O 2011 S. Karger AG, Basel } \\
\text { ISSN 1662-0631 } \\
\text { www.karger.com/crg }\end{array}$ \\
\hline
\end{tabular}

previous OPTIMOX-1 study, the suspension of oxaliplatin was considered to have no influence on the antitumor effects in this patient. In the OPTIMOX-1 study, we compared two groups who underwent 6 courses of FOLFOX therapy followed by FOLFOX4 therapy until tumor aggravation or 12 courses of sLV5FU2 therapy followed by 6 courses of FOLFOX7 therapy, but observed no significant difference in the median aggravation-free survival period between the two groups. The results of OPTIMOX-1 study demonstrated that a 'stop-and-go' approach employing oxaliplatin-free interval resulted in decreased neurotoxicity but did not affect overall survival in patients receiving FOLFOX as initial therapy for metastatic colorectal cancer [4]. The OPTIMOX-2 study suggests that chemotherapy-free interval is not recommended for patients with advanced colorectal cancer [5]. Since the antitumor effects of Cape used alone on metastatic colorectal cancer has been reported to be similar to that of intravenous 5-FU/leucovorin therapy, we considered that oral Cape administration was also appropriate in this patient [6]. In patients who have received primary treatment involving $\mathrm{BV}$, prolongation of the survival period by continuous BV administration has been reported [7]. Another study on BV + Cape therapy showed a response rate of $34 \%$ and an aggravation-free period of 10.8 months [8]. Results of the ECOG3200 study reported that use of single-agent BV is not recommended since it was shown to have inferior efficacy compared with FOLFOX alone or FOLFOX + BV treatment arms [9]. Finally, the patient made a decision not of chemotherapy-free interval but of BV + Cape therapy (BV $7.5 \mathrm{mg} / \mathrm{kg}$ on day 1 plus Cape $1,500 \mathrm{mg} / \mathrm{m}^{2}$ twice daily on days $1-14$, every 3 weeks) continuance along with improvement of her general status.

In out patient partial response was observed after 11 courses of BV + mFOLFOX6 therapy. After 6 subsequent courses of BV + Cape therapy, persistent peripheral neuropathy disappeared and partial response continued, showing successful tumor control. We intend to resume oxaliplatin administration after talking with the patient. To continue treatment using regimens involving oxaliplatin, the aggravation of peripheral neuropathy should be avoided. This case suggests that BV + Cape therapy can be a maintenance therapy during the suspension of oxaliplatin administration. 


\begin{tabular}{r|l|l|l}
$\begin{array}{r}\text { Case Reports in } \\
\text { Gastruenterology }\end{array}$ & $\begin{array}{l}\text { Case Rep Gastroenterol 2011;5:28-32 } \\
\text { DOI: 10.1159/000323138 }\end{array}$ & $\begin{array}{l}\text { Published online: } \\
\text { January 14, 2011 }\end{array}$ & $\begin{array}{l}\text { O 2011 S. Karger AG, Basel } \\
\text { ISSN 1662-0631 } \\
\text { www.karger.com/crg }\end{array}$ \\
\hline
\end{tabular}

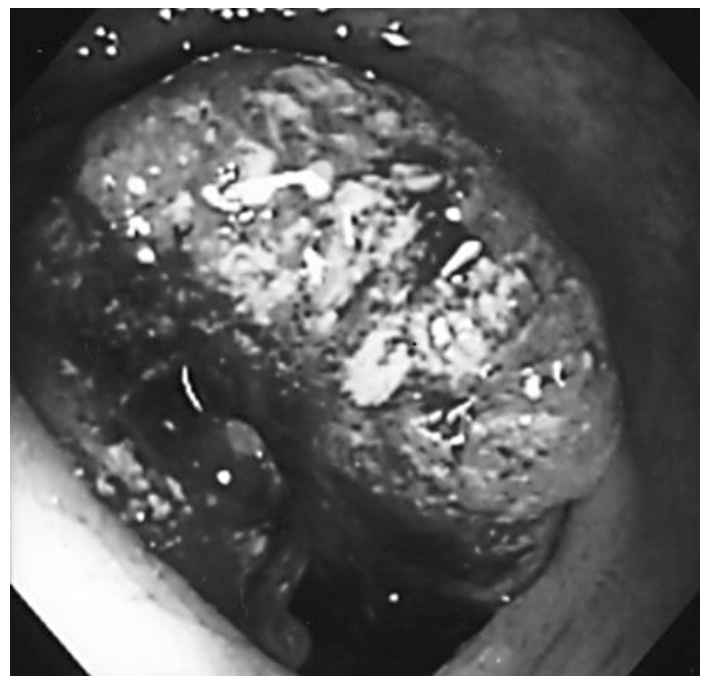

Fig. 1. Colonoscopy. A type 2 tumor in $2 / 3$ circumferential extension over the rectosigmoid. Biopsy revealed moderately differentiated adenocarcinoma.
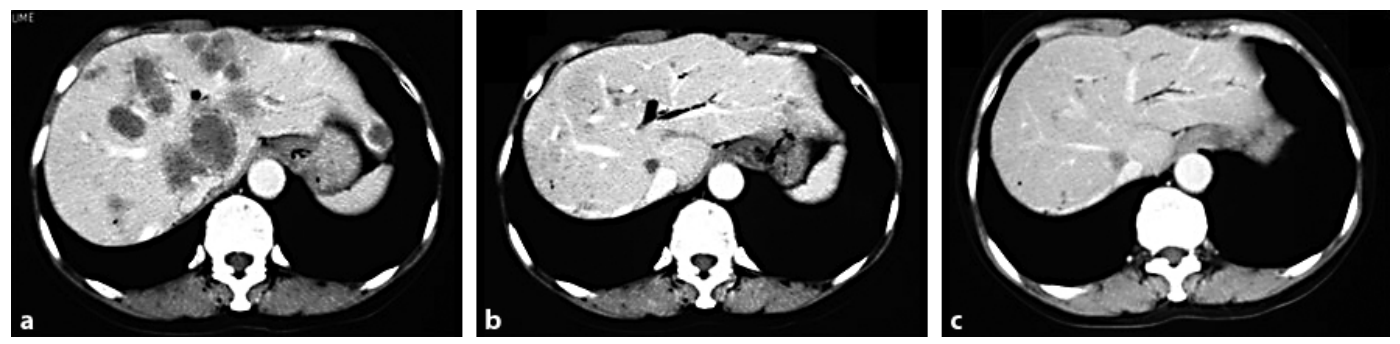

Fig. 2. Abdominal contrast-enhanced CT. a At initial examination, multiple metastatic lesions were observed throughout the liver. b At the end of 6 courses of BV + mFOLFOX6 therapy, the tumor had almost disappeared (complete remission). c At the end of 6 courses of BV + Cape therapy, complete remission was maintained without an increase in tumor size. 


\begin{tabular}{r|l|l|l}
$\begin{array}{r}\text { Case Reports in } \\
\text { Gastruanteriology }\end{array}$ & $\begin{array}{l}\text { Case Rep Gastroenterol 2011;5:28-32 } \\
\text { DOI: 10.1159/000323138 }\end{array}$ & $\begin{array}{l}\text { Published online: } \\
\text { January 14, 2011 }\end{array}$ & $\begin{array}{l}\text { O 2011 S. Karger AG, Basel } \\
\text { ISSN 1662-0631 } \\
\text { www.karger.com/crg }\end{array}$ \\
\hline
\end{tabular}

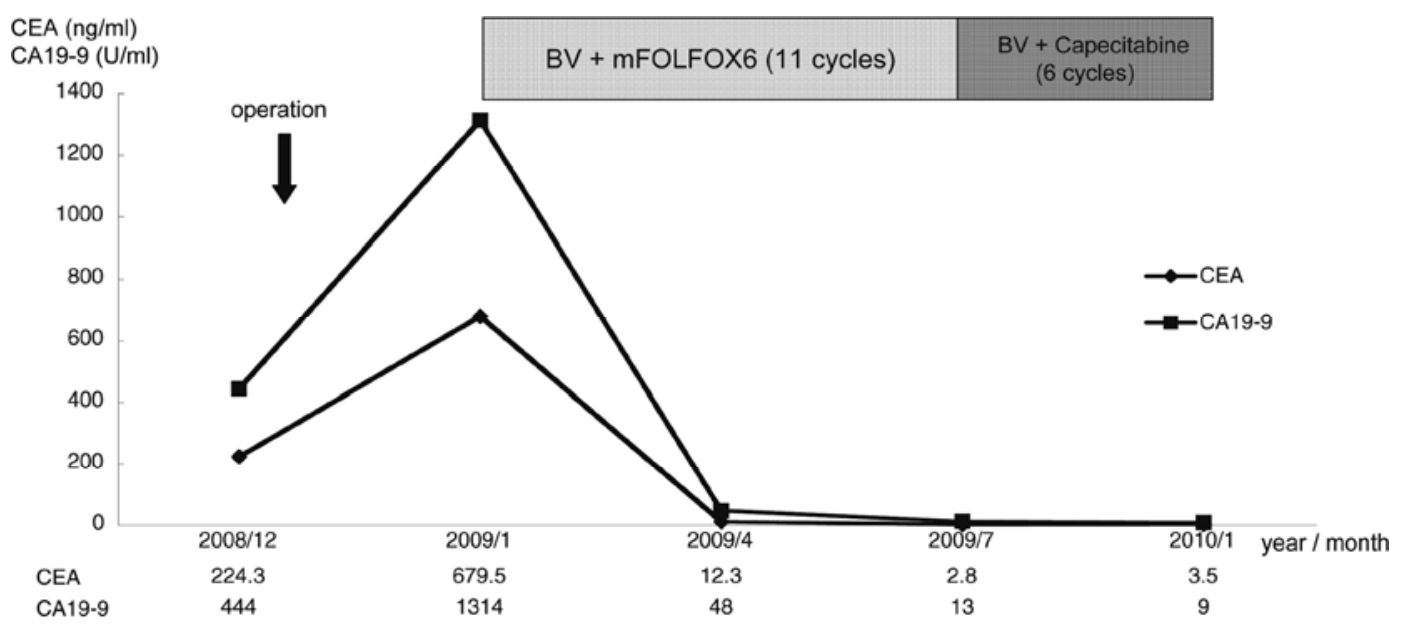

Fig. 3. Treatment course and changes in tumor markers. The CEA and CA19-9 levels increased before surgery but decreased to values below the normal range after 11 courses of BV + mFOLFOX6 therapy. This therapy was changed to BV + Cape therapy. At present, after 6 courses of BV + Cape therapy, the tumor markers are within the normal range. 2008/12: before surgery (at initial consultation); 2009/01: after surgery (before initiation of chemotherapy); 2009/04: after 6 courses of BV + mFOLFOX6 therapy; 2009/07: after 11 courses of BV + mFOLFOX6 therapy; 2010/01: after 6 courses of BV + Cape therapy.

\section{References}

$\checkmark 1$ de Gramont A, Figer A, Seymour M, et al: Leucovorin and fluorouracil with or without oxaliplatin as first-line treatment in advanced colorectal cancer. J Clin Oncol 2000;18:2938-2947.

2 Saltz LB, Clarke S, Díaz-Rubio E, et al: Bevacizumab in combination with oxaliplatin-based chemotherapy as first-line therapy in metastatic colorectal cancer: a randomized phase III study. J Clin Oncol 2008;16: 2013-2019.

3 Matsuo K, Higuchi M, Sasaki Y, et al: Analysis of a case of oxaliplatin-induced persistence sensory neuropathy. Gan To Kagaku Ryoho 2010;37:551-554.

-4 Tournigand C, Cervantes A, Figer A, et al: OPTIMOX1: a randomized study of FOLFOX4 or FOLFOX7 with oxaliplatin in a stop-and-go fashion in advanced colorectal cancer - a GERCOR study. J Clin Oncol 2006;24:394-400.

5 Chibaudel B, Maindrault-Goebel F, Lledo G, et al: Can chemotherapy be discontinued in unresectable metastatic colorectal cancer? The GERCOR OPTIMOX2 Study. J Clin Oncol 2009;27:5727-5733.

-6 Hoff PM, Ansari R, Batist G, et al: Comparison of oral capecitabine versus intravenous fluorouracil plus leucovorin as first-line treatment in 605 patients with metastatic colorectal cancer: results of a randomized phase III study. J Clin Oncol 2001;19:2282-2292.

7 Grothey A, Sugrue MM, Purdie DM, et al: Bevacizumab beyond first progression is associated with prolonged overall survival in metastatic colorectal cancer: results from a large observational cohort study (BRiTE). J Clin Oncol 2008;26:5326-5334.

8 Feliu J, Safont MJ, Salud A, et al: Capecitabine and bevacizumab as first-line treatment in elderly patients with metastatic colorectal cancer. Br J Cancer 2010;102:1468-1473.

-9 Giantonio BJ, Catalano PJ, Meropol NJ, et al: Bevacizumab in combination with oxaliplatin, 5-FU, and leucovorin (FOLFOX4) for previously treated metastatic colorectal cancer: results from the Eastern Cooperative Oncology Group Study E3200. J Clin Oncol 2007;25:1539-1544. 